\title{
Rupture of Previously Scarred Uterus
}

ASMA GUL

Department of Obstetrics \& Gynaecology: Postgraduate Medical Institute/Lahore General Hospital, Lahore

Correspondence to Dr: Asma Gul, Assistant Professor.

Objective:-to determine causative factors, find out associated maternal and faetal morbidity and mortality and to discuss preventive measures. Design:-A prospective study. Place and duration of study: Department of Obs. And Gynae, Lahore General Hospital, (PGMI). Lahore for a period of four years, Jan. 2002 to Dec. 2003.Subject and methods: - This study was conducted on sixty patients, with rupture of previously scarred uterus. Results: -Total number of deliveries during these four years was 15,628 . Rupture of uterus occurred in $0.47 \%$ cases $(1: 214)$. Out of these rupture of previously scarred uterus accured in $82 \%$ cases. Most of the patients were between ages $21-30$ years unbooked illiterate, belonged to poor class. $83 \%$ caesarean sections had been done in some peripheral non teaching hospitals. $13 \%$ patients had no labour pains at time of admission. The maternal mortality in this study was $3.33 \%$ and fetal mortality was $60 \%$. Conclusion:-First caesarean section should only be done if genuinely indicated, by some skilled obstetrician, in well equipped hospital. Patients with scarred uterus should be educated to have regular antenatal checkup and hospital delivery in next pregnancy.

Key words: Caesarea section, uterine rupture. Mortality, Maternal health services.

Rupture of gravid uterus is an obstetrical catastrophe and is associated with high maternal and perinatal mortality ${ }^{1.2}$. Nowadays, the most common cause of uterine rupture is rupture of previous scar. Rupture of uterus can be (I) complete which involves entire thickness of uterine wall and visceral peritoneum. Foetus and placenta may be expelled into the peritoneal cavity. (ii) Incomplete rupture or scar dehiscence when the uterine muscles have given away but visceral peritoneum in intact ${ }^{3}$.

The main reason for rupture of uterus in that despite of previous caesarean sections, the patients take trial at home by traditional birth attendants, who assure them for vaginal delivery and scare them that if they will go to the hospital, caesarean section would be done again. Moreover the rate of caesarean section is increasing day by day in our country, it has led to the emergence of serious problems.

This study was conducted in Department of Obstetrics and Gynaecology, Lahore General Hospital, Lahore, which is affiliated with post Graduate Medical Institute, Lahore. LGH is a tertiary cáre center where patients are referred from all the southern areas of Lahore as well as villages of Kasur and adjacent districts. The aims of this study were to determine the causative factors responsible for rupture of previously scarred uterus, to find out associated maternal and fetal morbidity and mortality and to discuss preventive measures.

\section{Patients and methods:}

This was a prospective study carried out for a period of four years i.e. from Jan 2000- Dec 2003 in the said department only those cases of rupture were included who had one or more previous caesarean section. A detailed history was taken including that of present and past pregnancies. Patient's age, parity, social class, booking status and educational status was enquired. Information's were taken regarding number of previous caesarean sections, place of previous surgery. Indications and complication, duration of this labour, interference by TBA and use of any medication. A full general, systemic and obstetrical examination was then carried out. Time taken from home or rural health centre to the hospital was noted and problems of transportation were considered.

\section{Results:}

During the study period there were 15,628 deliveries in our unit. Rupture of uterus occurred in 73 cases making an incidence of 1 per 214 births or $0.47 \%$. Out of these 73 cases, $60(82 \%)$ had previous caesarean section.

Majority of the patients had age between 21-30 years, parity $3-5,85 \%$ belonged to poor class. $96.66 \%$ were none booked, $95 \%$ were illiterate (Table 1) Gestational age varied between $37-42$ weeks. As the patients come from far flung areas so transport problem were seen in nearly all the patients. Only 5 patients brought there previous discharge card, in rest of the patient's information was collected from the patient her self or her attendants.

Table 1 Distribution of patients age and parity

\begin{tabular}{lll}
\hline Age in years & $\mathrm{N}=$ & \%age \\
\hline $15-20$ & 6 & 10 \\
$21-30$ & 35 & 58.33 \\
$31-40$ & 17 & 28.33 \\
$41-50$ & 2 & 03.33 \\
\hline Parity & & \\
\hline $1-2$ & 23 & 38.33 \\
$3-5$ & 34 & 56.66 \\
$>5$ & 3 & 5 \\
\hline
\end{tabular}

\begin{tabular}{lll}
\hline Social Class & & \\
\hline Lower middle class & 9 & 15 \\
Poor class & 15 & 85 \\
\hline
\end{tabular}

\begin{tabular}{lll}
\hline Booking Status & & \\
\hline Booked & 2 & 15 \\
Non booked & 58 & 85 \\
\hline
\end{tabular}

\begin{tabular}{lll} 
Education & & \\
\hline Illiterate & 57 & 95 \\
Upto class 5 & 5 & 5 \\
\hline
\end{tabular}


Table II shows patients characteristics regarding previous caesarean section. $50 \%$ patients had previous one caesarean section. 83.33 of the caesarean sections were done on some peripheral non teaching hospitals. As previous discharge cards were not available in most of the cases so we had no documentation of extension of tears, if previous classical caesarean section was done or any intra operative complications. In $25 \%$ patients they don't know the indication for previous caesarean section, while majority of the caesarean sections were done due to CPD, failure to progress and fetal distress. 15 patients gave history of wound infection, gaped wound and restitching.

Table II Patients Characteristics

\begin{tabular}{lll}
\hline No. of previous caesarean sections. & $\mathrm{n}=$ & \%age \\
\hline One & 30 & 50 \\
Two & 21 & 35 \\
Three & 9 & 15 \\
\hline
\end{tabular}

Place of previous caesarean section

\begin{tabular}{llll}
\hline Teaching Hospital & 10 & 16.66 \\
Peripheral Hospital & & 50 & 83.33 \\
\hline & & & \\
Indications & & & \\
\hline CPD & 18 & 30 \\
Failure of progress & 8 & 13.33 & \\
Foetal distress & 12 & 20 & \\
Malpresentation & 7 & 11.66 \\
Patient don't know & 15 & 25 \\
\hline
\end{tabular}

Duration of labour is depicted in table III Eight patients were not in labour at time of admission and were diagnosed during elective caesarean section. Rest of he patients were diagnosed as a case of rupture uterus before delivery, so they were opened up, none of them were delivered vaginally. Types of interferences carried out by TBA/LHV included direct I/M syntocinon injection, PGE2 vaginal tablets, uterine massage and internal manipulations. In $60 \%$ patients there was complete rupture of uterus while scar dehiscence occurred in $40 \%$ patients (Table IV). Caesarean hysterectomy was done in only 5 patients, in rest, repair was done either alone or with bilateral tubal ligation.

Regarding post operative complications, patients had more than one complication. $90 \%$ patients were anemic. Maternal mortality was $3.33 \%$ (Table V), while fetal mortality was $60 \%$ (Table VI). Average hospital stay of patients was 12 days.

Table III Duration of labour

\begin{tabular}{lll}
\hline Duration (hours) & $\mathrm{n}=$ & \%age \\
\hline Nil & 8 & 13.33 \\
$1-6$ & 4 & 6.66 \\
$7-12$ & 30 & 50.00 \\
$13-24$ & 10 & 16.66 \\
$>24$ & 8 & 13.33 \\
\hline
\end{tabular}

Table IV Outcome and management

\begin{tabular}{lll}
\hline & $\mathrm{n}=$ & $\%$ age \\
\hline Scar dehiscence & 24 & 40 \\
Rupture of uterus & 36 & 60 \\
Rupture of urinary bladder & 5 & 8.33 \\
Broad ligament haematoma & 7 & 11.66 \\
Cervical tear & 8 & 13.33 \\
Repair of uterus & 20 & 33.33 \\
Repair of uterus + BTL & 35 & 58.33 \\
Caesarean hysterectomy & 5 & 8.33 \\
\hline
\end{tabular}

Table V Maternal morbidity

\begin{tabular}{lll}
\hline Complication & $\mathrm{n}=$ & \%age \\
\hline Anemia & 54 & 90 \\
Fever & 36 & 60 \\
Wound infection & 12 & 20 \\
Urinary tract infection & 8 & 13.33 \\
Burst abdomen & 2 & 3.33 \\
DVT & 1 & 1.66 \\
Maternal death & 2 & 3.3 \\
\hline
\end{tabular}

Table VI Fetal morbidity

\begin{tabular}{lll}
\hline & $\mathrm{n}=$ & \%age \\
\hline Fetal death & 36 & 60 \\
Baby with $\mathrm{A} / \mathrm{S}>5$ & 16 & 26.66 \\
Baby with $\mathrm{A} / \mathrm{S}<5$ & 8 & 13.33 \\
\hline
\end{tabular}

\section{Discussion:}

About $83 \%$ of ruptures occurred in patients with a history of previous caesarean section hence the presence of prior uterine scar was the major contributing factor. In the studies carried out in Karachi ${ }^{4}$, Lahore $^{5}$ and Faisalabad ${ }^{6}$, the corresponding figure was $47 \%, 58 \%$ and 37 respectively. A study reported from Kuwat ${ }^{7}$ revealed $56 \%$ of rupture was attributed to previous uterine scar. The increase incidence in our study may be due to the fact that most of our patients were uneducated, belonged to poor social class and came from far flung areas. The long distance from referral hospital, rough roads, primitive mode of transport and reluctance to operative delivery again made them high rest for rupture uterus.

In this study $50 \%$ of the patients had previous one caesarean section, this is in contrast to study by Iskander ${ }^{8}$, who reported this figure to be $67 \%$. It was noted that despite of previous one, two or even three caesarean sections patients took trial at home or at small centre in the village, where all sorts of injudicious interventions were tried without considering the grave consequences. The health education of rural people, the training and supervision of TBA and availability of transport may reduce incidence of uterine rupture?

During the last two decades the rate of caesarean section had been doubled and trippled. In small clinics and centers most of the caesarean sections are done without legitimate indication by unskilled persons resulting in various problems. Extension of incision and tears during previous surgery and accurance of post operative infective 
morbidity especially endometritis increases the risk of rupture in next pregnancy due to weak scar formation. This should be told to the patient during daily rounds and documented properly without hiding the facts. They should be educated to keep the previous discharge slip, have regular antenatal checkup in next pregnancy and hospital delivery. The most important cause of rupture in this study was process of labour not monitored properly. According to a study from karachi ${ }^{10}$ prolonged active phase of labour was found to be associated with increase risk of uterine rupture.

Repair of uterus was done in $33 \%$ patients, repair with bilateral tubal ligation in $58 \%$ and caesarean hysterectomy was done in $8 \%$ cases. In study from Quetta ${ }^{11}$ corresponding figure were $9.1 \%, 86.5 \%$ and $4.5 \%$. GreenWood ${ }^{12}$ et. al. suggested the option of embolization of internal illiac artery with gel foam in order to reduce intra and post partum hemorrhage.

The maternal mortality is high in cases of uterine rupture because of hypovolemic, septic and neurogenic shock ${ }^{13}$. It was $3 \%$ which is lower than that reported in studies from Ethiopia ${ }^{14}$. Perinatal mortality was $60 \%$, it was lower than that reported from Zambia ${ }^{9}$, where it was $100 \%$.

\section{Conclusion}

1. First caesarean section should only be done if genuinely indicated, by some skilled obstetrician, in well equipped hospital.

2. At time of discharge patient should be educated to home regular antenatal checkup and hospital delivery in next pregnancy.

3. The discharge slip should be complete, mentioning any extension of tears during caesarean section, post operative endometritis, wound infection.

4. Trial of scar should be carried out only in teaching hospital with one to one monitoring by experience staff.

5. There should be public awareness programmes that no TBA or nurse should handle any patient with previous caesarean section, refer it to teaching hospital.
Particular attention to regulation of training and practice of TBA is required.

6. There should be motivation of the couples to seek family planning advice.

\section{References}

1. Chen KC, Hsieh TT. Rupture of gravid uterus: an eight years clinical analysis and review of the literature. Chang Gung Medical Journal 1992; 15:15-22.

2. Arshad Chohan; uterine rupture: Fundamentals of Obstetrics $1^{\text {st }}$ edition 2004, 374-377.

3. Saad Rana: Obstetrical trauma: Obstetrical and Prenatal care for developing countries $1^{\text {st }}$ edition 1998, 1306-1341.

4. Nagina Fatima: Rupture of uterus at term: JCPSP 1998 vol 8 (3): 137-139

5. Rakshan Shaheen Najmi: Rupture of previously scared uterus: A preventable catastrophy. JCPSP 1996 vol 6(6): 316-18.

6. Roohi M, Sajida C. Incidence of ruptured uterus DHQ hospital, Faisalabad: the professional 1994; 1: 53-57.

7. M.H Al Salem, M. Makhseed, M.A Ahmad. Rupture of gravid uterus: Experience of the maternity hospital, Kuwait Medical Principal and Practice, 2000, 9: 97-105.

8. Iskander M.N, Sali EG. Risk of lower segment scar rupture after multiple sections. J Obstet Gynaecol 1992; 12: 19-21.

9. Mulumba Nkata: Rupture of uterus: a review of 32 cases in General Hospital in Zambia. BMJ 1996; 312: 1204-1205.

10. Khans KS, Rizvi A, Rizvi JH. Risk of uterine rupture after the partographic 'alert' line is crossed: an additional dimension in the quest towards safe motherhood in labour following caesarean section: J Pakistan Med. Assoc. 1996; 46: 120-122.

11. Sabeena Qadeer: Management of rupture uterus: JCPSP 1999 vol9 (4): 190-192.

12. Greenwood L.M et. al: Obstetrics and nonmalignant Gynaecology treatment with angiographic embolization . Radiol 1987: 55-64.

13. Puff P, Mayed KS, Reed JA, Outcome of trial of labour in patients with single previous low transverse caesarean section for dystocia: Obstet and Gynecol 1988: 7: 38 .

14. Chamiso B, Rupture of pregnant uterus in Shashemene General Hospital South Shoa, Ethiopia (A three years study of 57 cases) Ethiop Med J 33. 1995; 4: 251-257. 